\title{
LEVATOR TRANSPOSITION PROCEDURE: A REVIEW OF 35 CASES
}

\author{
RUTH M. MANNERS, PAUL ROSSER and J. RICHARD O. COLLIN \\ London
}

\begin{abstract}
SUMMARY
Background. Levator transposition is used as a unilateral procedure for patients with both ptosis and aberrant movements of the eyelid. Muscular neurotisation occurs in the transposed levator muscle and thus some levator function is restored.

Method. We reviewed 35 patients who had undergone a levator transposition procedure.

Results. Twenty-eight patients had jaw-winking ptosis, three had cyclic oculomotor palsy and four had a third nerve palsy with aberrant regeneration. The follow-up period was between 1 and 39 months (mean 12 months). Eighteen patients were followed up for at least 12 months and their results were analysed as a separate group.

Conclusions. The levator function attained following transposition is related to the pre-operative voluntary function and this relationship is statistically significant (Wilcoxon test $\boldsymbol{p}<0.001$ ). Maximal levator function may not be achieved until 12 months post-operatively. The procedure is successful in abolishing aberrant eyelid movements and treating ptosis but the majority of patients require an additional levator resection to achieve a satisfactory lid height.
\end{abstract}

Causes of ptosis which involve unwanted movements of the upper lid include Marcus Gunn jaw-winking ptosis, aberrant regeneration of the third cranial nerve and cyclic oculomotor palsy. In certain cases the surgical correction of the ptosis should also aim to abolish the unwanted eyelid movements. To achieve this, the levator palpebrae superioris muscle (levator) needs to be transected or to have a portion excised. This is then combined with a brow suspension procedure. ${ }^{1,2}$

Dryden et al. ${ }^{3}$ described a technique where the levator was transected above the levator aponeurosis (aponeurosis) and sutured to the arcus marginalis.

From: Moorfields Eye Hospital, City Road, London EC1V 2PD, UK.

Correspondence to: Miss R. M. Manners, FRCOphth, Southampton Eye Unit, Tremona Road, Southampton SO16 6YD, UK.
Neuhaus ${ }^{4}$ felt it appropriate to use the discarded levator as the suspensory material. He reported a case in which he transected the muscle $25 \mathrm{~mm}$ above the tarsal plate leaving the normal attachments of the levator aponeurosis intact, divided it into three muscular strips and used these as suspensory strands.

Work by Lemagne et al. ${ }^{5}$ on Cynomolgus monkeys revealed that after levator transposition to frontalis muscle, muscular neurotisation occurs. Motor nerve fibres of the facial nerve invade the levator and, in time, the new axons develop synaptic connections which re-innervate the paralysed muscle. Lemagne described his own method of levator transposition ${ }^{6}$ in which the muscle is severed as far back in the orbit as possible and burrowed under orbicularis oculi muscle to be sutured to frontalis in the forehead. Once neurotisation is complete, the restoration of adequate levator function allows subsequent levator resection to be performed. A series of 35 patients who had undergone a levator transposition were reviewed to assess the effectiveness of the procedure and the amount of levator function restored.

\section{SURGICAL METHODS}

Levator transposition procedures were performed between May 1988 and January 1994 on patients with unilateral ptosis and aberrant movements of the levator palpebrae superioris muscle who preferred not to have bilateral surgery. All surgical procedures were performed as follows. An incision was made at the intended skin crease and the levator muscle found. ${ }^{7}$ This was traced as far back into the orbit as possible and its lateral borders identified. The complete muscle was held over a squint hook and clamped near its origin with a microhaemostat and adjacent to that with a Princess clamp, ensuring that the superior rectus muscle had been identified and avoided. The levator muscle was severed between the clamps and, at the origin only, cauterised.

An assessment was made of the effect of traction on the levator and if resultant elevation of the lid was

Eye (1996) 10, 539-544 ㅇ 1996 Royal College of Ophthalmologists 
Table I. Patient details

\begin{tabular}{|c|c|c|c|c|c|c|c|c|c|c|c|c|c|c|}
\hline Patien & t Sex & Cause of ptosis & $\begin{array}{l}\text { Previous } \\
\text { surgery }\end{array}$ & $\begin{array}{l}\text { Ptosis } \\
(\mathrm{mm})\end{array}$ & $\begin{array}{c}\mathrm{LF} \\
(\mathrm{mm})\end{array}$ & $\begin{array}{c}\text { Age at } \\
\text { surgery } \\
\text { (years) }\end{array}$ & $\begin{array}{l}\text { Aponeurosis } \\
\text { advanced }\end{array}$ & $\begin{array}{l}\text { s Movement } \\
\text { abolished }\end{array}$ & $\begin{array}{l}\text { Follow-up } \\
\text { (months) }\end{array}$ & $\begin{array}{l}\text { Post-trans. } \\
\text { ptosis } \\
(\mathrm{mm})\end{array}$ & $\begin{array}{l}\text { Final LF } \\
(\mathrm{mm})\end{array}$ & $\begin{array}{l}\text { Further } \\
\text { surgery }\end{array}$ & $\begin{array}{l}\text { Final ptosis ph } \\
(\mathrm{mm})\end{array}$ & $\begin{array}{l}\text { Lago- } \\
\text { hthalmos } \\
(\mathrm{mm})\end{array}$ \\
\hline 1 & $\mathbf{M}$ & MG (lat) & - & 4 & 11 & 4.5 & - & No & 36 & 3 & 6 & ALR & 0 & 1 \\
\hline 2 & $\mathrm{~F}$ & COP & $\times 1$ for $L X T$ & 8 & 1 & 24 & + & Yes & 6 & 3 & 0 & - & & \\
\hline 3 & $\mathrm{~F}$ & MG (lat) & - & 5 & 8 & 4.5 & + & Yes & 39 & 4 & 3 & ALR & 2 & 2 \\
\hline 4 & $\mathrm{~F}$ & MG (lat) & - & 3 & 10 & 12.5 & + & Yes & 28 & 3 & 4 & ALR & 0 & 2 \\
\hline 5 & $\mathrm{~F}$ & MG (lat \& med) & - & 3 & 14 & 10.5 & + & Yes & 18 & 3 & 4 & ALR & 3 & 0 \\
\hline 6 & $\mathrm{~F}$ & MG (lat) \& SR- & Knapp/ALR & 4 & 3 & 10 & - & Yes & 29 & 4 & 5 & - & 4 & 5 \\
\hline 7 & M & MG (lat) \& SR- & Knapp & 7 & 8 & 9 & + & Yes & 18 & 2 & 2 & - & & \\
\hline 8 & $\mathrm{~F}$ & COP & - & 3 & 0 & 19 & + & Yes & 1 & 1.5 & 1 & - & & \\
\hline 9 & $\mathrm{~F}$ & MG (lat) & - & 3 & 10 & 4 & + & Yes & 26 & 3 & 5 & ALR & 0 & 1 \\
\hline 10 & $\mathrm{M}$ & MG (lat) & - & 3.5 & 10 & 12.5 & + & Yes & 1 & 2 & 1 & & & \\
\hline 11 & $\mathrm{~F}$ & MG (med) & - & 3 & 10 & 9 & + & Yes & 12 & 3 & 5 & ALR planned & & \\
\hline 12 & $\mathbf{M}$ & MG (lat) \& SR- & Knapp & 4 & 12 & 6.5 & + & Yes & 18 & 0 & 6 & - & & \\
\hline 13 & $\mathrm{~F}$ & MG (lat) \& LET & - & 6 & 6 & 6 & + & Yes & 1 & 7 & 2 & Urgent MM BS & & \\
\hline 14 & $\mathrm{M}$ & Partial III with ab. regeneration & $\times 5$ for $\mathrm{RXT}$ & 2 & 13 & 15 & + & Yes & 5 & 4 & 4 & - & & \\
\hline 15 & M & Traumatic III with ab. regeneration & $\times 2$ for $\mathrm{LXT}$ & 3 & 13 & 14 & + & Yes & 21 & 2 & 4 & - & & \\
\hline 16 & M & MG (lat) \& SR - & - & 3 & 13 & 7.5 & + & Yes & 20 & 2 & 4 & ALR & 0 & 0 \\
\hline 17 & $\mathrm{~F}$ & MG (lat) & - & 3 & 7 & 8 & + & Yes & 4 & 5 & 3 & - & & \\
\hline 18 & $\mathbf{M}$ & MG (lat) & - & 6 & 7 & 4.5 & + & Yes & 4 & 5 & 0 & - & & \\
\hline 19 & $\mathbf{M}$ & MG (lat) & - & 4 & 8 & 7.5 & + & Yes & 6 & 1 & 2 & - & & \\
\hline 20 & $\mathbf{M}$ & MG (lat) & - & 4 & 7 & 5 & + & Yes & 13 & 2 & 4 & - & & \\
\hline 21 & $\mathbf{M}$ & MG (lat), SR - \& RXT & $\times 2$ for $\mathrm{RXT}$ & 7 & 5 & 13 & + & Yes & 18 & 1.5 & 3 & - & & \\
\hline 22 & $\mathbf{M}$ & MG (lat), SR - \& RET & - & 4 & 11 & 16.5 & + & Yes & 4 & 2 & 1 & - & & \\
\hline 23 & $\mathbf{M}$ & MG (med) & - & 3 & 17 & 7 & + & Yes & 10 & 0 & 2 & - & & \\
\hline 24 & $\mathrm{~F}$ & MG (lat) \& SR- & - & 3 & 9 & 53 & + & No & 1 & 4 & 3 & - & & \\
\hline 25 & $\mathbf{M}$ & MG (med), SR - \& RET & - & 4 & 7 & 8 & + & Yes & 12 & 3 & 2 & MM BS & & \\
\hline 26 & $\mathrm{~F}$ & MG (lat), SR - \& LET & Knapp $/ \times 1$ for LET & 7 & 8 & 4 & + & Yes & 1 & 5 & 0 & - & & \\
\hline 27 & $\mathbf{M}$ & MG (med) \& SR- & Knapp & 2 & 13 & 35 & + & Yes & 18 & 3 & 7 & ALR & 0 & 0 \\
\hline 28 & $\mathrm{~F}$ & Traumatic III + ab. regeneration & $\times 1$ for LXT & 8 & 1 & 27 & + & Yes & 15 & 3 & 4 & MM BS & & \\
\hline 29 & $\mathbf{M}$ & COP & $\times 1$ for $L X T$ & 9 & 0 & 15 & + & Yes & 6 & 3 & 1 & - & & \\
\hline 30 & $\mathrm{~F}$ & MG (med) & - & 2 & 12 & 18 & + & Yes & 6 & 2 & 3 & - & & \\
\hline 31 & $\mathbf{M}$ & MG (lat) \& SR- & - & 6 & 6 & 5.5 & + & Yes & 18 & 2 & 4 & ALR planned & & \\
\hline 32 & $\mathbf{M}$ & Congen. III with ab. innervation. & $\times 5$ for $\mathrm{LXT}$ & 9 & 0 & 11.5 & - & Yes & 1 & 5 & 0 & & & \\
\hline 33 & $\mathrm{~F}$ & MG (lat) \& SR - & - & 6 & 6 & 5 & + & Yes & 4 & 5 & 2 & - & & \\
\hline 34 & $\mathbf{M}$ & MG (lat) \& SR- & Knapp/ALR & 3 & 10 & 11 & + & Yes & 10 & 0 & 0 & - & 0 & 0 \\
\hline 35 & $\mathbf{M}$ & MG (lat) \& SR- & Knapp/ALR & 5 & 5 & 22.5 & + & Yes & 12 & 0 & 5 & - & 0 & 0 \\
\hline
\end{tabular}

LF, levator function; MG, Marcus Gunn (synkinetic pterygoid muscle); COP, cyclic oculomotor palsy; SR-, superior rectus underaction; III, third nerve palsy; ab., aberrant; L, left; R, right; XT, exotropia; ET, esotropia; ALR, anterior levator resection; MM BS, Mersilene mesh brow suspension. 
poor then the lateral horn connections were cut. An incision above the eyebrow was made down to frontalis muscle and a tunnel formed through preseptal orbicularis oculi and pre-aponeurotic fat. The levator was pulled up through the tunnel using sinus forceps. Once delivered into the brow incision, pull-out 4/0 nylon sutures were placed at each lateral border and brought out as high as possible through the forehead skin using free needles. The levator was sutured to the frontalis within the brow wound using 6/0 long-acting absorbable sutures whilst the nylon sutures applied traction on the levator. These traction sutures were subsequently removed and the brow wound closed. The lid height was assessed and, if still low, an aponeurotic advancement was performed, preserving Müller's muscle to ensure an adequate blood supply to the levator muscle. ${ }^{8}$ The lid wound was closed, re-forming the skin crease.

Levator resection at a later date, following levator transposition, required a few modifications to the normal procedure. A cautious skin incision prevented cutting the levator muscle, which lay close to the skin surface. The borders of the muscle were identified medially and laterally and a squint hook passed under the belly of the muscle. Since Müller's muscle was preserved during the levator transposition, the plane between it and the conjunctiva was untouched. This virgin plane was dissected to free the levator muscle, which was then resected and sutured to the tarsal plate with 6/0 long-acting absorbable sutures. The skin crease was re-formed.

\section{PATIENTS}

Thirty-five patients underwent a levator transposition (Table I), of whom 20 were male and 15 female. There was a large age range from 4 to 53 years (mean 12.7 years, median 10 years). Surgery was on the right side in 17 and on the left in 18 patients. Thirtytwo of the 35 procedures included an aponeurosis advancement.

\section{Causes of Ptosis}

Twenty-eight patients had Marcus Gunn jaw-winking ptosis (22 had lateral pterygoid, 5 medial pterygoid (Fig. 1) and one both lateral and medial pterygoid synkinesis), 3 patients had cyclic oculomotor palsy (COP) and 4 had a third nerve palsy with aberrant innervation. All patients were embarrassed by the aberrant movements of the eyelid.

\section{Associated Strabismus Surgery}

Of the patients with Marcus Gunn ptosis, 10 had an isolated superior rectus weakness, of whom 6 underwent a Knapp procedure. ${ }^{9}$ Four patients had an esotropia, 3 with associated superior rectus weakness and 1 of these underwent a Knapp procedure together with bilateral lateral rectus recessions.
One patient had an exotropia with associated superior rectus weakness and underwent two procedures for the exotropia. All patients with third nerve palsies had undergone strabismus correction with up to five operations per patient. Two of the patients with COP had undergone surgery to correct permanent exotropias. All strabismus surgery was performed prior to levator transposition.

\section{Degree of Ptosis}

The degree of ptosis (measured as the lid position without the aberrant movement) varied from 2 to 9 $\mathrm{mm}$. The voluntary levator function was poor $(0-5 \mathrm{~mm})$ in 8 cases, moderate $(6-10 \mathrm{~mm})$ in 17 cases and good (11-17 mm) in 10 cases.

\section{Follow-up Period}

\section{RESULTS}

The period of follow-up was between 1 and 39 months (mean 12.1 months, median 12 months). Six patients each had short-term follow-up of only 1 month since they lived overseas, failed to attend their clinic appointments or underwent urgent brow suspension. All remaining patients had a minimum follow-up of 4 months. A group of 18 patients had a minimum follow-up of 12 months and their results were analysed separately.

\section{Aberrant Eyelid Movements}

Thirty-three of 35 patients had their aberrant movements abolished (Fig. 2). Two patients (nos. 1 and 24) had some remaining synkinetic movement of the eyelid. Patient 1 had a subsequent levator resection performed and during this procedure a remaining strand of untransposed levator was divided with abolition of the remaining jaw-wink. Patient 24 was 53 years old and was satisfied with the reduction in the aberrant lid movement.

\section{Degree of Ptosis}

At their last clinic visit following their levator transposition procedure, 24 patients had an improvement in their ptosis (of between 1 and $6 \mathrm{~mm}$ ), 6 had no change and 5 had worse ptosis than preoperatively (1-2 mm) (Fig. 3).

\section{Additional Ptosis Surgery}

Overall, 15 patients required additional ptosis surgery to their levator transposition. Three patients underwent brow suspension with Mersilene mesh following the levator transposition. In patient 13 this was performed urgently, 1 month later, due to the risk of development of amblyopia. Patients 25 and 28 both had brow suspension 12 months after initial surgery due to dissatisfaction with the result of initial surgery.

Ten patients had a levator resection in addition to 


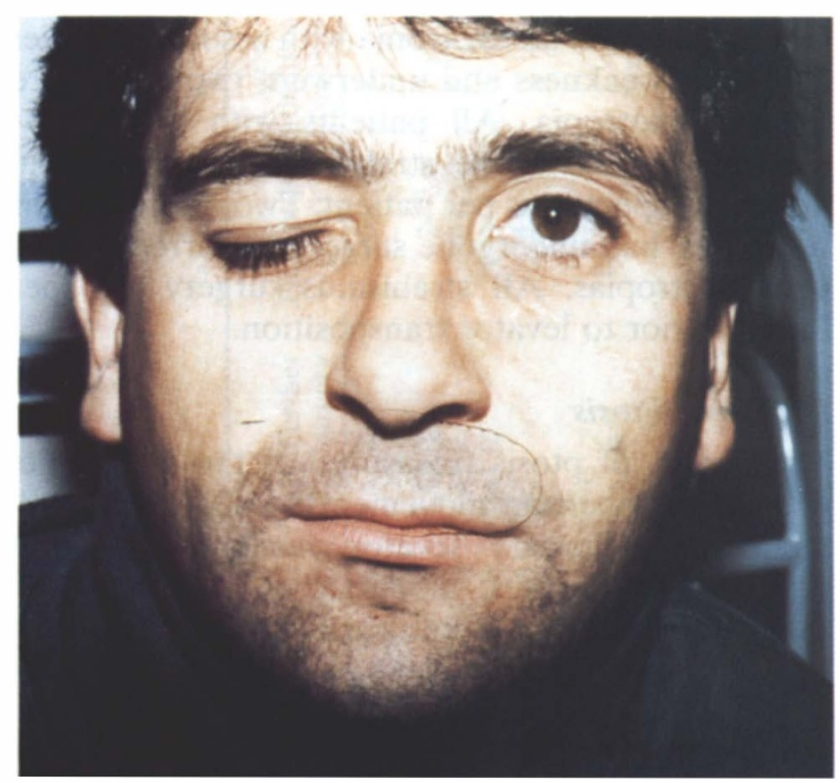

(a)

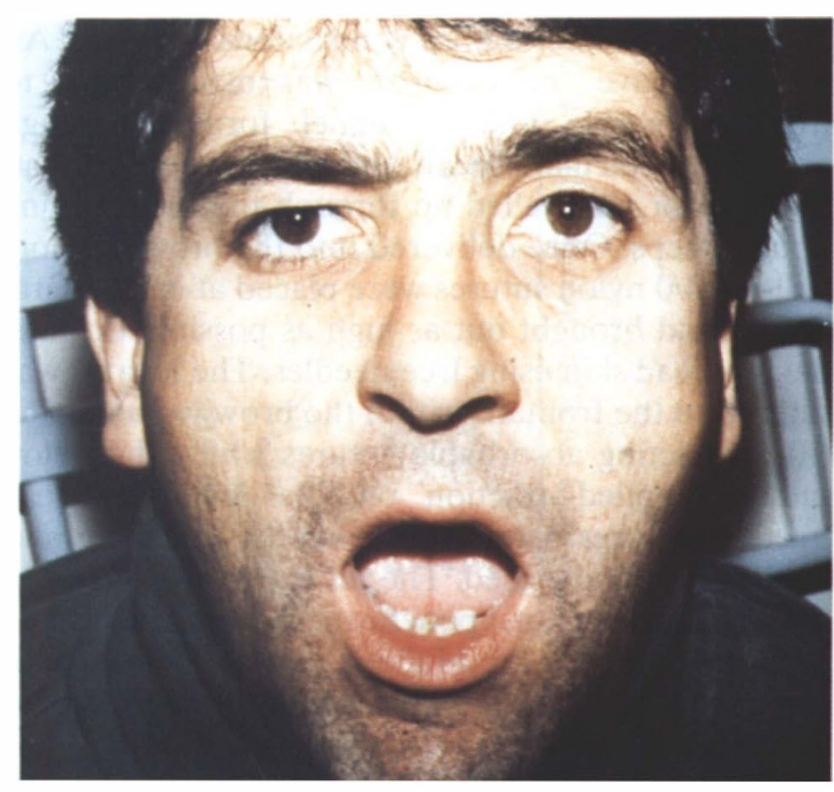

(b)

Fig. 1. Patient 27. Jaw-wink.

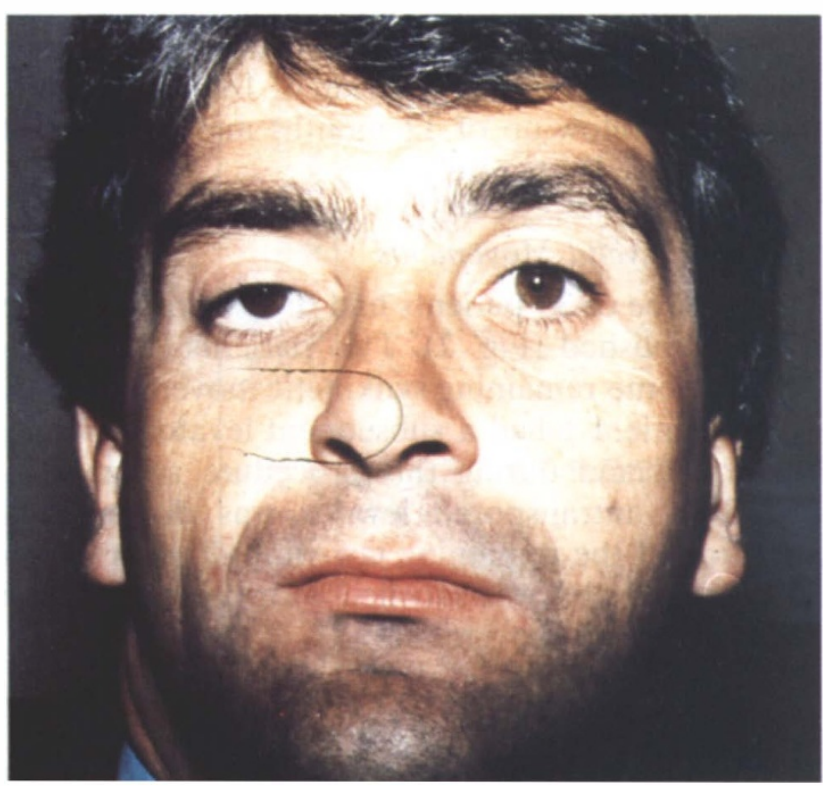

(a)

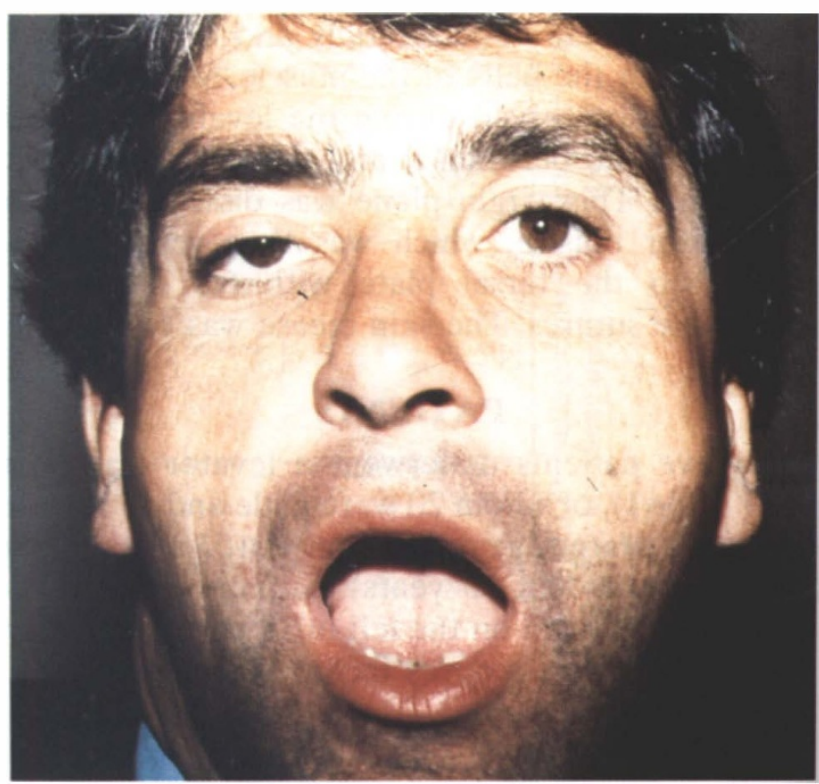

(b)

Fig. 2. Patient 27. Jaw-wink abolished following levator transposition.

their levator transposition. Three patients $(6,34$ and 35) had already had a levator resection before presenting to us. Two of these had no remaining ptosis at their final assessment and one had $4 \mathrm{~mm}$ of ptosis but was satisfied with the result. Seven patients underwent a levator resection between 18 and 39 months following their transposition; 5 patients $(1,4$, 9, 16 and 27) improved to no remaining ptosis (Fig. 4), 1 patient (3) had $2 \mathrm{~mm}$ of remaining ptosis and one patient (5) remained at $3 \mathrm{~mm}$ of ptosis. Four of the 8 patients who had both levator resection and levator transposition (3, 4, 6 and 9) had lagophthalmos of up to $5 \mathrm{~mm}$ but showed no signs of corneal exposure. Two patients (11 and 31) are awaiting levator resections, 18 months after their levator transposition.

\section{Levator Function}

Final recorded levator functions are shown in Fig. 5. Of the 18 patients with a minimum follow up of 12 months, 14 regained levator function of $4 \mathrm{~mm}$ or more. 


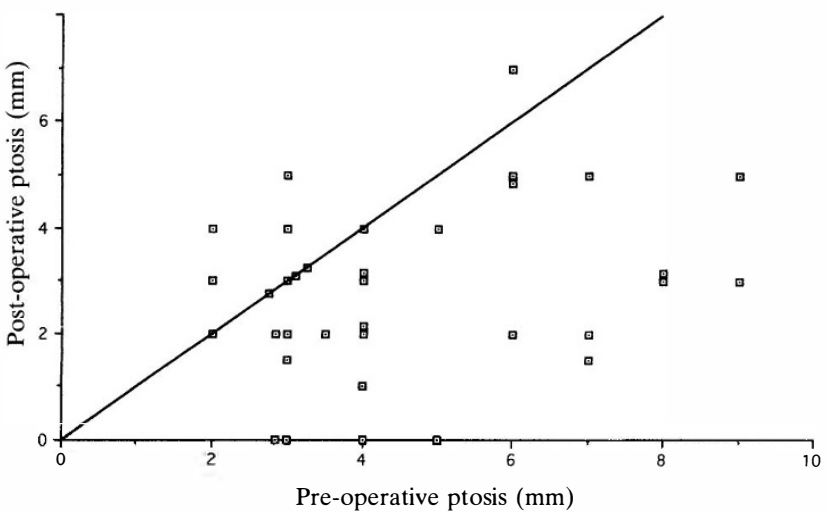

Fig. 3. Pre-operative ptosis compared with post-operative ptosis.

The pre-operative voluntary levator function (as opposed to the levator function with the aberrant movement) was compared with final levator function following levator transposition in patients with at least 12 months of follow-up (Fig. 6). The result was statistically significant using the Wilcoxon's rank sum test $(p<0.001)$.

\section{DISCUSSION}

The levator transposition procedure was initially proposed as a unilateral procedure to abolish aberrant eyelid movements and raise the eyelid in patients with Marcus Gunn jaw-winking ptosis. ${ }^{4,6}$ The theoretical advantage is that re-innervation of the transected levator muscle by muscular neurotisation from frontalis muscle enables some restoration of levator function. ${ }^{5}$ Betharia and Kumar ${ }^{10}$ reported the results of 15 cases in which levator transposition had been performed. However, they modified the procedure by transecting the levator muscle just above the superior suspensory ligament and using permanent Mersilene sutures to pull the muscle up into the brow. Thus the major effect of neurotisation of the levator was lost since this requires direct contact with healthy muscle.

In Lemagne's original descriptions of the procedure in humans, ${ }^{6,11}$ further levator surgery was

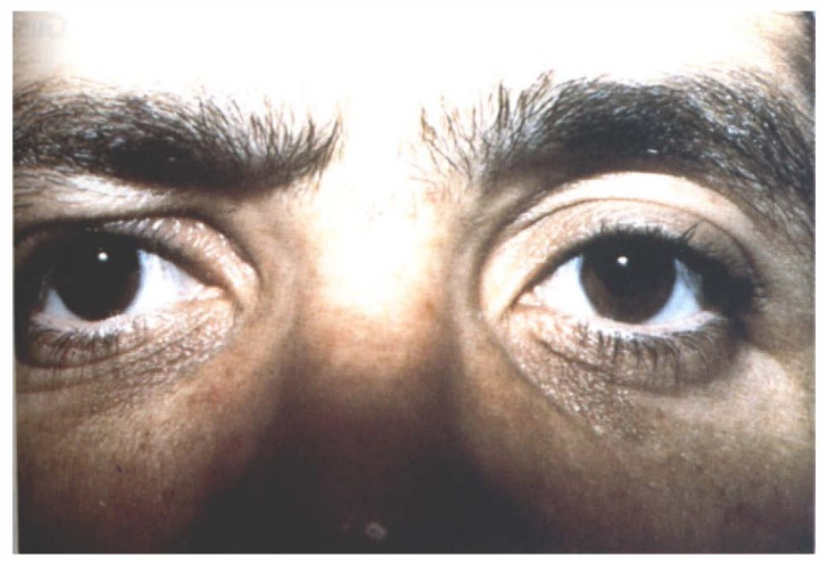

Fig. 4. Patient 27. Appearance following levator resection.

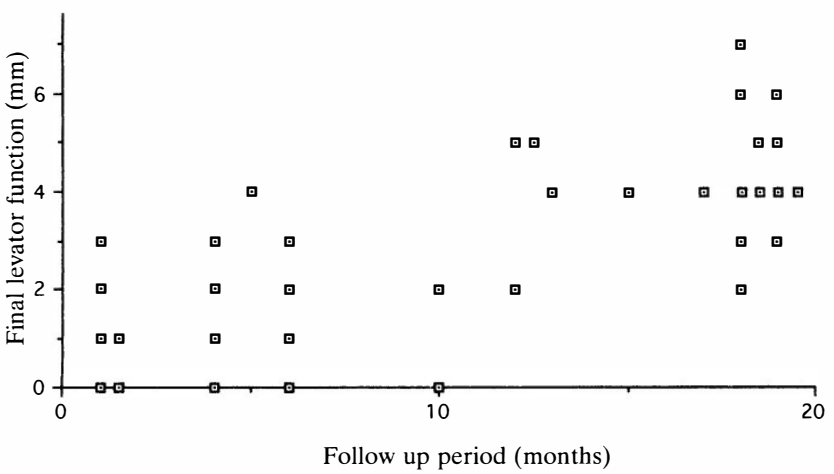

Fig. 5. Final recorded levator function plotted against time.

performed 6 months after the levator transposition. We found in this series that levator function continued to improve in several patients during the 6-12 month follow-up period and we therefore routinely make our patients wait 18 months before further ptosis surgery is undertaken.

The transposed levator acquires its nerve supply from the facial nerve. We presume that the mechanism for its action is secondary to that of the frontalis muscle which raises the brows in upgaze and thus coincidentally stimulates the transposed levator. In downgaze frontalis is relaxed and thus the input to the transposed levator ceases.

The post-transposition levator function was found to be related to the pre-operative voluntary levator function. A healthy muscle with many functioning neuromuscular units, i.e. good levator function, prior to transposition will have a better chance of regaining functioning neuromuscular units following transposition and subsequent neurotisation. The converse is also true.

A minimum levator function of $4 \mathrm{~mm}$ is generally required to allow a levator resection to be performed. However, following levator transposition, a levator resection performed as a secondary procedure will shorten the suspensory sling and therefore can be performed in patients with levator function of less than $4 \mathrm{~mm}$. One of our patients (3) with post-

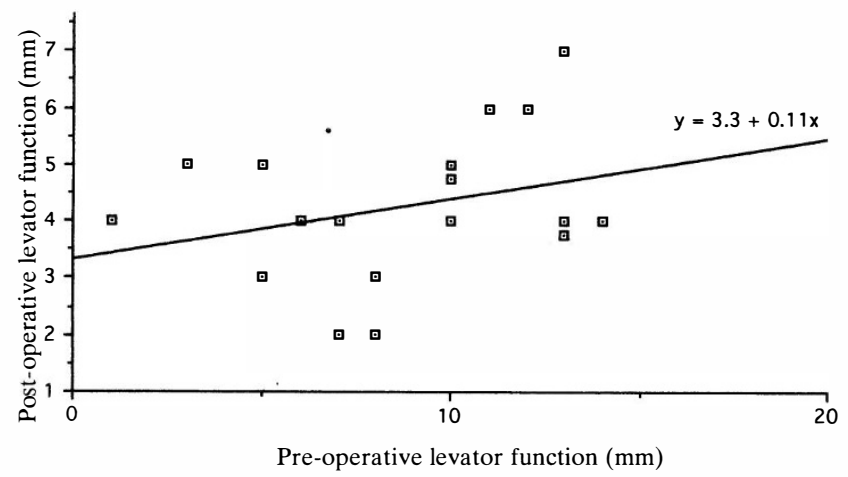

Fig. 6. Pre-operative levator function compared with postoperative levator function in patients with a minimum follow-up of 12 months. 
transposition levator function of $3 \mathrm{~mm}$ underwent a levator resection as a secondary procedure with a subsequent improvement in their ptosis.

Eighteen of our 35 patients had a follow-up period of at least 12 months and this group had their results analysed separately. Thirteen had a satisfactory result ( $2 \mathrm{~mm}$ or less ptosis). Of these, 6 had required levator resection after transposition and in 1 a levator resection was planned to improve the result further. In the remaining group of patients, the final result was unsatisfactory ( $3 \mathrm{~mm}$ or more ptosis) in 4 . Two had a levator resection, 1 prior to and 1 following levator transposition. Two patients required or requested brow suspension early. The final patient is awaiting a levator resection. This is summarised as follows:

Satisfactory ( $\leqslant 2 \mathrm{~mm}$ ptosis): 13 patients ( 7 with and 6 without levator resection).

Unsatisfactory ( $\geqslant 3 \mathrm{~mm}$ ptosis): 4 patients ( 2 with levator resection and 2 with subsequent brow suspension).

Pending: 1 patient awaiting a levator resection.

We have found that the levator transposition offers the following benefits:

No other source of suspensory material is required. Some levator function is restored to the lid postoperatively which is related to the initial voluntary levator function (Wilcoxon's rank sum test, $p<0.001$ ). This gives a more symmetrical result following unilateral surgery than a levator division and brow suspension.

There are also some disadvantages:

Final results may be delayed for more than 12 months.

Further levator resection is required in the majority of cases for cosmetically acceptable results. (However, the transposition procedure alone is of particular use in patients with third nerve palsies with aberrant movements where total correction of ptosis is often unacceptable because of a concurrent poor Bell's phenomenon.)

The pre-operative voluntary levator function appears to influence the maximum function restored to the muscle following transposition (Fig. 6). Thus, patients with poor initial levator function and severe ptosis may not achieve sufficient restoration of levator function in addition to the suspensory action of the transposition (even with a subsequent levator resection) to eradicate the ptosis.

We suggest that to achieve the best results from the levator transposition procedure, the selection criteria should include the following:

1. Patients selected should have unilateral aberrant eyelid movements which they find embarrassing and ptosis with moderate to good voluntary levator function.

2. In children there should be no immediate risk of amblyopia.

3. Patients should be warned that the best result may not be attained for more than a year and that there is a high chance they will require additional surgery after 18 months to eradicate the ptosis.

Key words: Aberrant-eyelid movement, Jaw-wink, Levator transposition, Ptosis.

\section{REFERENCES}

1. Crawford JS. Repair of ptosis using frontalis muscle and fascia lata. Trans Am Acad Ophthalmol Otolaryngol 1956;60:672-8.

2. Beard CA. New treatment for severe unilateral ptosis and for ptosis with jaw winking. Am J Ophthalmol 1965;59:252-8.

3. Dryden RM, Fleming JC, Quickert MH. Levator transposition and frontalis sling procedure in severe unilateral ptosis and the paradoxically innervated levator. Arch Ophthalmol 1982;100:462-4.

4. Neuhaus RW. Eyelid suspension with a transposed levator palpebrae superioris muscle. Am J Ophthalmol 1985;100:308-11.

5. Lemagne J-M, Brucher JM, Michiels J. Clinical, biochemical and histological results of a levator muscle transposition for ptosis in Cynomolgus monkeys. Orbit 1985;4:141-6.

6. Lemagne J-M. Transposition of the levator muscle and its reinnervation. Eye 1988;2:189-92.

7. Collin JRO. A manual of systematic eyelid surgery. 2nd ed. London: Churchill Livingstone, 1989;49-61.

8. Collin JRO. New concepts in the management of ptosis. Eye 1988;2:185-8.

9. Knapp P. Tr Am Ophthalmol Soc 1969;67:304-21.

10. Betharia SM, Kumar S. Levator sling for Marcus Gunn ptosis. Br J Ophthalmol 1987;71:685-9.

11. Lemagne J-M. Frontalis transposition of levator palpebrae superioris in a patient with Marcus Gunn ptosis. Bull Soc Belge Ophtalmol 1986;219:13-9. 